\title{
Evaluation of Sandwich Enzyme-Linked Immunosorbent Assay and Reverse Transcription Polymerase Chain Reaction for the Diagnosis of Foot-and-Mouth Disease
}

\author{
Salman Khan ${ }^{a}$ Syed Asad Ali Shah ${ }^{b}$ Syed Muhammad Jamal ${ }^{a}$ \\ aDepartment of Biotechnology, University of Malakand, Dir Lower, Pakistan; 'bivestock and Dairy Development \\ Department, Peshawar, Pakistan
}

\section{Keywords}

Foot-and-mouth disease $\cdot$ Foot-and-mouth disease virus - Kappa value · Test agreement - Enzyme-linked immunosorbent assay · Reverse transcription polymerase chain reaction

\begin{abstract}
Background: Foot-and-mouth disease (FMD) is an infectious and highly contagious disease of cloven-hoofed domestic and wild animals, causing heavy economic losses to the livestock industry. Rapid and reliable diagnosis of the disease is essential for the implementation of effective control measures. This study compared sandwich enzyme-linked immunosorbent assay (S-ELISA) and conventional reverse transcription polymerase chain reaction (RT-PCR) for the diagnosis of FMD. Methods: A total of 60 epithelial samples from suspected cases of FMD were tested using both S-ELISA and RT-PCR assays. The level of agreement between the assays was assessed by calculating the Kappa value. Results: S-ELISA detected 38 (63\%) samples positive for FMD virus (FMDV). Being predominant, serotype O was detected in 22 (57.9\%) of the total samples tested positive, whereas 9 (23.7\%) and 7 (18.4\%) samples were found positive for serotypes $A$ and Asia-1, respectively. RT-PCR detected viral genome in 51 $(85 \%)$ of the samples using pan-FMDV primers set, 1F/1R.
\end{abstract}

Thirty-six samples were found positive and 7 negative by both the tests. The level of agreement between the tests was assessed by calculating the Kappa value, which was found to be fair (Kappa value $=0.303$ and $95 \% \mathrm{Cl}=0.089 ; 0.517$ ) and significant ( $p=0.009$ ). However, 2 samples, which were found positive on S-ELISA tested negative on RT-PCR. This may beattributed to the presence of nucleotide mismatch(es) in the primer-binding sites that may have resulted in failure of amplification of the viral genome. The serotype-specific RT-PCR assays not only confirmed serotyping results of SELISA but were also able to establish serotype in 9 S-ELISAnegative but pan-FMDV RT-PCR-positive samples. Conclusions: The RT-PCR assay contributes significantly to establishing a quick, sensitive, and definitive diagnosis of FMD in resource-constrained countries. Samples giving negative results in S-ELISA should be tested in RT-PCR for the disease detection and virus typing.

๑ 2021 S. Karger AG, Basel

\section{Introduction}

Foot-and-mouth disease (FMD) is a highly infectious and contagious transboundary disease affecting about 70 species of cloven-hoofed domestic and wild animals including bovines, ovines, caprines, and swines [1]. It is a karger@karger.com www.karger.com/int
(C) 2021 S. Karger AG, Basel

Karger!
Correspondence to:

Syed Muhammad Jamal, jamal115@yahoo.com 
severely debilitating disease, characterized by vesicles in the mouth and on the muzzle, feet, and teats and a cause of death in young animals. The causative agent, FMD virus (FMDV), is a single-stranded, positive-polarity RNA virus that belongs to the genus Aphthovirus of the family Picornaviridae [2]. It is one of the smallest viruses, with a size of about $28 \mathrm{~nm}$ in diameter and spherical in shape. The viral genome is approximately $8.4 \mathrm{~kb}$ [3] and is surrounded by a capsid made up of 60 capsomers. Each capsomer consists of a single molecule of 4 polypeptides, namely, VP1, VP2, VP3, and VP4, which are coded by viral genome. VP1 is the outermost and one of the most variable capsid polypeptides that is believed to be a major immunogenic protein [2].

FMDV exists in 7 genetically and antigenically distinct types called serotypes that are A, O, C, Asia-1, SAT1, SAT2, and SAT3. There are a large number of subtypes within each serotype that exhibit a spectrum of antigenic characteristics [4-6], and new subtypes arise with time. Based on geographical distribution, the FMDV subtypes belonging to different serotypes have been classified into 7 different pools [7-9].

FMD causes enormous economic losses to the livestock industry of the affected countries resulting from of high morbidity in adult animals and death in young animals mainly due to myocarditis [1]. Infected animals lose weight and are prone to secondary infections, and the disease can cause long-term loss of productivity, for example, reduced milk yield $[10,11]$. Within infected premises, a high proportion of the animals often become infected since the virus spreads easily between animals, but there is only low-level mortality (except in young animals). There is also loss of working efficiency in draught animals in some developing countries. FMD critically impacts food security and limits access to international markets for trade in livestock and animal products due to sanitary measures [12].

Due to the rapid spread of the disease and heavy economic losses that arise from the outbreak, fast, sensitive, and specific diagnosis of the disease is necessary. Furthermore, as clinical signs similar to FMD can be caused by other viruses $[13,14]$, it is essential that laboratory analysis is performed on suspected cases. In addition, determination of the serotype of FMDV involved in the outbreak is necessary in infected countries where vaccination is practiced to control the disease. Different techniques are used for FMD diagnosis and virus typing, including sandwich enzyme-linked immunosorbent assay (S-ELISA) and reverse transcription polymerase chain reaction (RTPCR).
S-ELISA [15-17] is extensively used for FMD diagnosis and virus typing. However, this assay gives positive results with only about $70-80 \%$ of epithelial suspensions that contain FMDV [15]. Therefore, suspensions of SELISA-negative specimens are propagated in sensitive cell cultures [15], and viral growth is confirmed by S-ELISA. Up to 4 additional days are required to show the presence or absence of FMDV, especially when the virus loads are too low to be detected by S-ELISA or no FMDV exists. These limitations delay the implementation of control measures to contain the disease.

RT-PCR is a valuable tool in the detection of FMDV [18] as it offers the benefits of reliable and rapid diagnosis. Amplification of the immuno-dominant VP1 coding region in RT-PCR and its subsequent sequencing helps determine the serotype and subtype, may reveal the origin of the disease, and supports the possibility of preventing further outbreaks by selection of the most appropriate vaccine for a region where vaccination is practiced.

FMD is endemic in Pakistan, and 3 serotypes of FMDV (i.e., serotypes $\mathrm{O}, \mathrm{A}$, and Asia-1) are responsible for outbreaks in the country [16]. The complement fixation test was initially used for the disease diagnosis and virus typing in Pakistan, which was replaced by S-ELISA in 2002. Later on, RT-PCR-based detection and virus typing were also established. Outbreaks due to serotype O FMDV are predominant in the country, followed by serotype Asia-1 and A viruses [16]. Each serotype has evolved into multiple strains, the dominant being O-PanAsia-II, A-Iran05, and Group-VII (Sindh-08), within serotypes O, A, and Asia-1 FMDVs, respectively [19-22]. Outbreaks of the disease have been associated with animal movement [16]. The present study aimed to compare the results obtained using S-ELISA on the epithelial tissues collected in the field and submitted for FMD diagnosis, with results obtained from RT-PCR using a pan-FMDV primer set for the highly conserved $5^{\prime}$-UTR (untranslated region) of the viral genome.

\section{Materials and Methods}

\section{Sample Preparation}

Epithelial samples from bovines with clinical signs suspected for FMD were collected from different parts the country. The samples were collected by the veterinarians/para-veterinary staff, stored in buffer glycerin, and transported to the Department of Biotechnology, University of Malakand, in ice packs. The samples were stored at $-20^{\circ} \mathrm{C}$ before processing. The samples were ground, and a $10 \%$ suspension was made in phosphate-buffered saline as described in the Office International des Epizooties (OIE) Manual of Diagnostic Tests and Vaccines for Terrestrial Animals [23]. The 
Table 1. Oligonucleotide primers used for conventional RT-PCR-based diagnosis of FMD and virus typing

\begin{tabular}{|c|c|c|c|c|c|}
\hline \multirow[t]{2}{*}{ Pan-FMDV } & $1 \mathrm{~F}$ & GCCTGGTCTTTCCAGGTCT & Forward & 5'UTR & $\sim 330$ \\
\hline & $1 \mathrm{R}$ & CCAGTCCССTTCTCAGATC & Reverse & 5'UTR & - \\
\hline \multicolumn{6}{|l|}{ Serotype-specific } \\
\hline $\mathrm{O}$ & $\mathrm{O}-1 \mathrm{C}_{272}$ & TBGCRGGNCTYGCCCAGTACTAC & Forward & $1 C(272-294)$ & $\sim 1,150^{*}$ \\
\hline A & $A-1 C_{562}$ & TACCAAATTACACACGGGAA & Forward & $1 \mathrm{C}(562-581)$ & $\sim 865^{*}$ \\
\hline
\end{tabular}

FMD, foot-and-mouth disease; FMDV, foot-and-mouth disease virus; RT-PCR, reverse transcription polymerase chain reaction. * With EUR-2B 52 .

suspension was centrifuged at 2,000 $\mathrm{g}$ for $10 \mathrm{~min}$, and the supernatant was collected for detection of FMDV using S-ELISA. The remaining epithelial suspension was subjected to RNA extraction.

Sandwich Enzyme-Linked Immunosorbent Assay (S-ELISA)

The S-ELISA (Pirbright, UK) was performed following Roeder and Le Blanc Smith [17] and Ferris and Dawson [15], as described previously [16]. An absorbance value of $\geq 0.1$ above the background indicated positive result.

\section{RNA Isolation}

Whole RNA was isolated from the epithelial suspensions using TRI Reagent (Sigma, Germany) following instructions of the manufacturer. The extracted RNA was precipitated by the addition of ethanol and resuspended in a $50 \mu \mathrm{L}$ volume of RNase-free water. A negative control (water) was included each time during RNA isolation. The isolated RNA was processed for cDNA synthesis.

cDNA Synthesis and RT-PCR

RT-PCR was carried out by first synthesizing cDNA using a random hexamer primer. In brief, the extracted RNA was reversetranscribed in a $20 \mu \mathrm{L}$ reaction mixture containing $10 \mathrm{mM}$ each of the $4 \mathrm{dNTPS}$ and $1 \mu \mathrm{l}$ of a random hexamer primer. The mixture was incubated at $42^{\circ} \mathrm{C}$ for $60 \mathrm{~min}$ to synthesize the first strand cDNA and was then kept at $70^{\circ} \mathrm{C}$ for $10 \mathrm{~min}$ to stop the reaction. The cDNA was stored at $-20^{\circ} \mathrm{C}$ till further use.

The cDNA was amplified using the pan-FMDV primer set $(1 \mathrm{~F} / \mathrm{R})$, located at $5^{\prime}$-UTR of the viral genome [24] (Table 1). The thermal cycler conditions used were as follows: 1 cycle of $94^{\circ} \mathrm{C}$ for $5 \mathrm{~min}$, followed by 35 cycles of $94^{\circ} \mathrm{C}$ for $60 \mathrm{~s}, 55^{\circ} \mathrm{C}$ for $60 \mathrm{~s}, 72^{\circ} \mathrm{C}$ for $45 \mathrm{~s}$, a final extension at $72^{\circ} \mathrm{C}$ for $5 \mathrm{~min}$, and then holding at $4^{\circ} \mathrm{C}$. A negative control (water) was included in every set of amplifications.

Samples that gave a positive result in the S-ELISA and panFMDV RT-PCR were further amplified in PCR using serotypespecific primers set described elsewhere $[25,26]$. For serotyping, the cDNA was amplified using primer sets shown in Table 1 . The amplification was carried out using $50 \mu \mathrm{L}$ of PCR mixture containing $25 \mathrm{mM}$ of $\mathrm{MgCl}_{2}, 25 \mathrm{mM}$ of each dNTP, 10X buffer and $20 \mu \mathrm{M}$ of each primer, $5 \mathrm{U} / \mu \mathrm{L}$ of Taq polymerase, $12 \mu \mathrm{L} c \mathrm{DNA}$, and water to a final volume of $50 \mu \mathrm{L}$ in a $0.5-\mathrm{mL}$ capacity PCR tube. The thermal cycler conditions used were as follows: 1 cycle of $94^{\circ} \mathrm{C}$ for 5 min followed by 35 cycles of $94^{\circ} \mathrm{C}$ for $60 \mathrm{~s}, 57^{\circ} \mathrm{C}$ for $60 \mathrm{~s}, 72^{\circ} \mathrm{C}$ for $80 \mathrm{~s}$, a final extension at $72^{\circ} \mathrm{C}$ for $10 \mathrm{~min}$, and then holding at $4^{\circ} \mathrm{C}$. A negative control (water) was included in every set of amplifications.

\section{Gel Electrophoresis}

A $7 \mu \mathrm{L}$ volume of each of the amplified RT-PCR products was run with a DNA ladder on $1.5 \%$ agarose gel. The DNA bands with the expected fragment size (Table 1) were observed using an ultraviolet transilluminator and photographed by a gel documentation system (Vilbert Lourmat, France).

\section{Statistical Analysis}

The level of agreement between S-ELISA and RT-PCR was ascertained by calculating the Kappa value using statistical package, SPSS version 13.

\section{Results}

\section{Sandwich Enzyme-Linked Immunosorbent Assay}

A total of sixty epithelial specimens from animals suspected for FMD were tested. Of these, 38 (63\%) samples tested positive for FMDV by S-ELISA. FMDV serotype $\mathrm{O}$ was found in 22 (57.9\%) of the S-ELISA-positive epithelial samples, whereas $9(23.7 \%)$ and 7 (18.4\%) epithelial samples tested positive for FMDV serotypes A and Asia1 , respectively.

\section{Reverse Transcription Polymerase Chain Reaction}

Of the 60 samples suspected for FMD, 51 (85\%) tested positive for the viral genome using the pan-FMDV primer set, 1F/1R. RT-PCR of the samples using this primer set resulted in amplification of a 330-bp fragment of FMDV genome. Of the 51 samples positive in pan-FMDV RT-PCR, 26, 10, and 9 were found positive for serotypes O-, A-, and Asia-1-specific RT-PCR assays, respectively. 
Table 2. Comparison between S-ELISA and RT-PCR results for the detection of FMDV

\begin{tabular}{lllr}
\hline Test result & $\begin{array}{l}\text { ELISA-positive, } \\
n(\%)\end{array}$ & $\begin{array}{l}\text { ELISA-negative, } \\
n(\%)\end{array}$ & $\begin{array}{l}\text { Total, } \\
n(\%)\end{array}$ \\
\hline PCR-positive & $36(60)$ & $15(25)$ & $51(85)$ \\
PCR-negative & $02(3.3)$ & $07(11.7)$ & $9(15)$ \\
\hline Total & $38(63.3)$ & $22(36.7)$ & $60(100)$ \\
\hline
\end{tabular}

FMDV, foot-and-mouth disease virus; S-ELISA, sandwich enzyme-linked immunosorbent assay; RT-PCR, reverse transcription polymerase chain reaction.

\section{Comparison between S-ELISA and RT-PCR}

Thirty-six samples tested positive for the FMD viral antigen by both S-ELISA and RT-PCR, whereas 7 samples tested negative in both the tests. Fifteen samples which tested negative by S-ELISA were found positive in RTPCR. However, 2 samples which tested positive in S-ELISA were found negative in RT-PCR (Table 2). The level of agreement between S-ELISA and RT-PCR was assessed by calculating the Kappa value using SPSS version 13 . The level of agreement between the 2 tests was found to be fair (Kappa value $=0.303$ with $95 \%, C I=0.089 ; 0.517$ ).

All the S-ELISA-positive samples tested positive in RT-PCR using serotype-specific primers. Serotyping results of RT-PCR were $100 \%$ in agreement with those of S-ELISA. Furthermore, the S-ELISA-negative but panFMDV RT-PCR-positive samples $(n=15)$ were also tested using serotype-specific primer sets. The serotype-specific RT-PCRs classified 6, 1, and 2 samples as positive for serotypes $\mathrm{O}, \mathrm{A}$, and Asia-1 FMDV, respectively, while the serotype of 6 samples, positive in pan-FMDV RT-PCR, could not be ascertained.

\section{Discussion}

Rapid, sensitive, and accurate diagnosis is important for early and effective control of any infectious disease including FMD. The presence of high concentration of FMDV in clinical specimens is easily detected by S-ELISA $[27,28]$. However, in some cases, the viral load is low which cannot be detected by S-ELISA. In such cases, virus isolation is necessary. However, culturing standard quality, ready-to-use primary or secondary cells are time-consuming, laborious, and expensive. Moreover, the presence of live virus in the sample is required for virus isolation which, in turn, depends on the quality of sample. The presence or absence of viral growth is confirmed using S-ELISA, which results in delay in implementation strategies for control of the disease.

Although S-ELISA is able to detect FMDV and ascertain serotypes of the virus in a single test, it relies on specific reagents (antibodies) which should be homologous to the outbreak viruses. Alternative techniques such as RT-PCR assays can be employed on samples which are negative by S-ELISA, either due to a low copy number of the virus, partially degraded viral antigen, or lack of homology between the S-ELISA reagents and the field viruses. The RT-PCR ingredients can be stored as ready to use and are more sensitive, faster, and easy to standardize [28-30]. Furthermore, nonreliance of RT-PCR on a biologically produced set of reagents (i.e., specific antibodies), the information on primers and other reagents, etc. make it easier to standardize diagnostics in developing countries where FMD is prevalent. However, RT-PCR has its own limitations, for example, additional tests are required to ascertain the serotype of FMDV (using serotype-specific primer sets) when the sample scores positive in pan-FMDV RT-PCR. Mutation in the FMDV genome in the primer-binding sites may result in false-negative results. In such cases, the primer set needs to be updated. Furthermore, PCR-based amplification techniques are prone to cross contamination, and therefore, proper handling of the samples and PCR products is required to avoid this issue. Although real-time RT-PCR assays have been reported for detection of FMD and virus typing [31, $32]$, these require expensive reagents and equipment which the developing countries cannot afford.

In the present study, S-ELISA and RT-PCR for diagnosis of FMD were compared using epithelial samples collected from animals suspected for FMD. S-ELISA detected FMDV in $63.3 \%$ of the samples, whereas $85 \%$ of the samples were found positive by RT-PCR. These findings are in concordance with Reid and colleagues [24] who reported 62 and $85 \%$ samples positive by S-ELISA and RT-PCR, respectively. Ferris and Dawson [15] also reported $61.7 \%$ epithelial samples positive by S-ELISA. The unsuccessful detection of FMDV in clinical specimens in the current study may either be due to poor quality of samples received in the laboratory or the specimens collected late in the convalescent stage of the infection when the virus concentration in the specimen may start waning or indeed be absent after clearance. Delayed reporting of the disease or/and late collection of specimen may be either due to lack of required resources, properly trained staff for collection of samples, or communication gap, especially in far-flung areas. Quality of the collected speci- 
mens may further deteriorate due to harsh environmental conditions, including high temperature, desiccation, extremes of $\mathrm{pH}$, and physiochemical stress [33]. Failure to detect FMDV in the specimens may also be due to the reason that the clinical signs observed were not due to FMDV.

Of a total of 60 samples, 36 tested positive and 7 negative by both the tests. Thus, there was agreement between the results obtained by the 2 assays for $71.7 \%$ of the specimens derived from suspect FMD cases. The level of agreement between S-ELISA and RT-PCR was found to be fair. The 95\% confidence intervals of the Kappa value are however wide, reflecting considerable uncertainty about the estimate. It may be attributed to the high sensitivity of RT-PCR over S-ELISA, which was found to be 1.34 times higher than that of S-ELISA under the conditions of this study. Thus, pan-FMDV RT-PCR was able to detect FMDV, in addition to $22 \%$ of the samples tested. However, 2 samples that tested positive by S-ELISA, tested negative by pan-FMDV RT-PCR. This discrepancy between the 2 assays may be due to the presence of nucleotide substitution(s) in the primer-binding site(s), resulting in failure of PCR amplification. The comparison between the 2 assays highlighted 17 samples (15 for SELISA and 2 for pan-FMDV RT-PCR) which failed to detect FMDV (antigen or genome) in one technique but gave a positive result in the other.

Samples which gave positive results in S-ELISA and pan-FMDV RT-PCR were successfully amplified using serotype-specific primer sets. The serotype-specific RTPCR assays also determined the serotype of FMDV in $60 \%$ of the samples $(n=9)$ that tested negative in S-ELISA but positive in pan-FMDV RT-PCR. However, serotyping could not be established in the remaining S-ELISAnegative and pan-FMDV RT-PCR-positive samples ( $n=$ 6). Failure of the serotype-specific assays to establish the serotype of FMDV in some pan-FMDV RT-PCR-positive samples may be due to the fact that the primer sets in the latter assay has been designed from a highly conserved region of the viral genome compared to that of the former assays, which have been designed from the less conserved region of genome of FMDV [34].

In conclusion, the RT-PCR can contribute significantly toward establishing a rapid, sensitive, and definitive diagnosis of FMD together with other well-developed assays such as S-ELISA. The diagnosis however may not be solely based on RT-PCR results; rather, it should be used as a supplementary test to S-ELISA. Samples giving negative results in S-ELISA should be tested by pan-FMDV RT-PCR. Samples positive by pan-FMDV RT-PCR should be further subjected to serotype-specific RT-PCR assays to ascertain the serotype of FMDV. This will minimize the chances of cross contamination with an amplification product and may eliminate the expensive management and necessity of going through propagating the virus in tissue culture and subsequent testing by S-ELISA in developing countries, where the disease in endemic.

\section{Acknowledgements}

We thank the farmers for their cooperation in sample collection from their animals.

\section{Statement of Ethics}

The authors confirm that the ethical policies of the journal, as noted on the journal's author guidelines page, have been adhered to. Informed consent was obtained from the enrolled subjects. No ethical approval was required as only standard samples were obtained from suspect cases of FMD for diagnostic purpose. This exemption was granted by the "Departmental Bio-ethical Committee" of the Department of Biotechnology, University of Malakand, vide reference number UoM/Biotech/DBC/007/15.

\section{Conflict of Interest Statement}

The authors have no conflicts of interest to declare.

\section{Funding Sources}

The authors did not receive any funding.

\section{Author Contributions}

S.M.J. and S.A.A.S. designed the research project. S.A.A.S. and S.K. collected samples. S.K. conducted the experiments. S.K. and S.M.J. wrote the manuscript. S.M.J. and S.A.A.S. reviewed the manuscript.

References

1 Alexandersen S, Mowat N. Foot-and-mouth disease: host range and pathogenesis. Curr Top Microbiol Immunol. 2005;288:9-42.

2 Belsham GJ. Distinctive features of foot-andmouth disease virus, a member of the picornavirus family; aspects of virus protein synthesis, protein processing and structure. Prog Biophys Mol Biol. 1993;60:241-60.

3 Rowlands DJ. Foot and mouth disease virus. In: Webster RG, Granoff A, editors. Encyclopedia of virology. London: Academic press; 1994. p. $488-496$. 
4 Bachrach HL. Foot-and-mouth disease. Annu Rev Microbiol. 1968;22:201-44.

5 Domingo E, Escarmís C, Baranowski E, RuizJarabo CM, Carrillo E, Núñez JI, et al. Evolution of foot-and-mouth disease virus. Virus Res. 2003;91:47-63.

6 Knowles NJ, Samuel AR. Molecular epidemiology of foot-and-mouth disease virus. Virus Res. 2003;91:65-80.

7 Di Nardo A, Knowles NJ, Paton DJ. Combining livestock trade patterns with phylogenetics to help understand the spread of foot and mouth disease in sub-Saharan Africa, the Middle East and Southeast Asia. Rev Sci Tech. 2011;30:63-85.

8 Sumption K, Domenech J, Ferrari G. Progressive control of FMD on a global scale. Vet Rec. 2012;170:637-9.

9 Jamal SM, Belsham GJ. Foot-and-mouth disease: past, present and future. Vet Res. 2013; 44:116.

10 Knight-Jones TJ, Rushton J. The economic impacts of foot and mouth disease: what are they, how big are they and where do they occur? Prev Vet Med. 2013;112:161-73.

11 Ferrari G, Tasciotti L, Khan E, Kiani A. Footand-mouth disease and its effect on milk yield: an economic analysis on livestock holders in Pakistan. Transbound Emerg Dis. 214; 61:e52-9.

12 Knight-Jones TJD, McLaws M, Rushton J. Foot-and-mouth disease impact on smallholders: what do we know, what don't we know and how can we find out more? Transbound Emerg Dis. 2017;64:1079-94.

13 Knowles NJ, Sellers RF. Swine vesicular disease. In: Beran GW, editor. Handbook of Zoonoses, section B: Viral. 2nd ed. Boca Raton, FL: CRC Press; 1994. p. 437-44.

14 Mann J, Sellers R. Foot-and-mouth disease virus. In: Horzinek M, editor. Virus infections of vertebrates. Virus infections of ruminants. Amsterdam Oxford New York Tokyo: Elsevier; 1990. Vol. 3; p. 503-12

15 Ferris NP, Dawson M. Routine application of enzyme-linked immunosorbent assay in comparison with complement fixation for the diagnosis of foot-and-mouth and swine vesicular diseases. Vet Microbiol. 1988;16(3): 201-9.

16 Jamal SM, Ahmed S, Hussain M, Ali Q. Status of foot-and-mouth disease in Pakistan. Arch Virol. 2010;155:1487-91.
17 Roeder PL, Le Blanc Smith PM. Detection and typing of foot-and-mouth disease virus by enzyme-linked immunosorbent assay: a sensitive, rapid and reliable technique for primary diagnosis. Res Vet Sci. 1987;43(2):225-32.

18 Marquardt O, Straub OC, Ahl R, Haas B. Detection of foot-and-mouth disease virus in nasal swabs of asymptomatic cattle by RT-PCR within 24 hours. J Virol Methods. 1995;53(23):255-61.

19 Jamal SM, Ferrari G, Ahmed S, Normann P, Belsham GJ. Genetic diversity of foot-andmouth disease virus serotype $\mathrm{O}$ in Pakistan and Afghanistan, 1997-2009. Infect Genet Evol. 2011;11(6):1229-38.

20 Jamal SM, Ferrari G, Ahmed S, Normann P, Curry S, Belsham GJ. Evolutionary analysis of serotype A foot-and-mouth disease viruses circulating in Pakistan and Afghanistan during 2002-2009. J Gen Virol. 2011;92(Pt 12): 2849-64.

21 Jamal SM, Ferrari G, Ahmed S, Normann P, Belsham GJ. Molecular characterization of serotype Asia-1 foot-and-mouth disease viruses in Pakistan and Afghanistan; emergence of a new genetic Group and evidence for a novel recombinant virus. Infect Genet Evol. 2011; 11(8):2049-62.

22 Ullah A, Jamal SM, Romey A, Gorna K, Kakar MA, Abbas F, et al. Genetic characterization of serotypes A and Asia-1 foot-and-mouth disease viruses in Balochistan, Pakistan, in 2011, in 2011. Transbound Emerg Dis. 2017; 64(5):1569-78.

23 OIE. Foot and mouth disease. Manual of standards, diagnostic tests and vaccines. 7th edn. Paris, France: Office International des Epizooties; 2012. Vol. 1; p. 190-217.

24 Reid SM, Ferris NP, Hutchings GH, Samuel AR, Knowles NJ. Primary diagnosis of footand-mouth disease by reverse transcription polymerase chain reaction. J Virol Methods. 2000;89:167-76.

25 Knowles NJ, Samuelv AR. Polymerase chain reaction amplification and cycle sequencing of the 1D (VP1) gene of foot-and-mouth disease viruses. Appendix 8. Report of the Open Session of the Research Group of the Standing Technical Committee of the European Commission for the control of foot-and-mouth disease. Vienna, Austria; 1994 Sep. Vol. 1922; p. 45-53.
26 Knowles NJ, Valarcher J-F, Zakharov VM, Scherbakov AV, Zihang Z, Shang Y, et al. Recent molecular epidemiology of foot-andmouth disease Asia-1. Appendix 14. Report of the Session of the Research Group of the Standing Technical Committee of the European Commission for the control of foot-andmouth disease (EUFMD). Held in Paphos. Cyprus. 2006 Oct;17-20:97-104.

27 Hamblin C, Armstrong RM, Hedger RS. A rapid enzyme-linked immunosorbent assay for the detection of foot-and-mouth disease virus in epithelial tissues. Vet Microbiol. 1984;9:435-43.

28 Reid SM, Forsyth MA, Hutchings GH, Ferris NP. Comparison of reverse transcription polymerase chain reaction, enzyme linked immunosorbent assay and virus isolation for the routine diagnosis of foot-and-mouth disease. J Virol Methods. 1998;70(2):213-7.

29 Sutmoller P, Cottral GE. Improved techniques for the detection of foot-and-mouth disease virus in carrier cattle. Arch Gesamte Virusforsch. 1967;21(2):170-7.

30 Callens M, De Clercq K, Gruia M, Danes M. Detection of foot-and-mouth disease by reverse transcription polymerase chain reaction and virus isolation in contact sheep without clinical signs of foot-and-mouth disease. Vet Q. 1998;20(Suppl 2):S37-40.

31 Reid SM, Mioulet V, Knowles NJ, Shirazi N, Belsham GJ, King DP. Development of tailored real-time RT-PCR assays for the detection and differentiation of serotype $\mathrm{O}, \mathrm{A}$ and Asia- 1 foot-and-mouth disease virus lineages circulating in the Middle East. J Virol Methods. 2014;207:146-53.

32 Jamal SM, Belsham GJ. Development and characterization of probe-based real time quantitative RT-PCR assays for detection and serotyping of foot-and-mouth disease viruses circulating in West Eurasia. PLoS One. 2015; 10(8):e0135559.

33 Shaw AE, Reid SM, King DP, Hutchings GH Ferris NP. Enhanced laboratory diagnosis of foot and mouth disease by real-time polymerase chain reaction. Rev Sci Tech. 2004; 23(3):1003-9.

34 Carrillo C, Tulman ER, Delhon G, Lu Z, Carreno A, Vagnozzi A, et al. Comparative genomics of foot-and-mouth disease virus. J Virol. 2995;79:6487-504. 